\title{
Resilience amongst medical students: a student's perspective
}

\author{
Sanketh Rampes, Anvarjon Mukhammadaminov, Kitt Dokal, Samineh Yousefi and Yasmin Amy Divecha \\ Faculty of Life Sciences \& Medicine, King's College London, London, UK
}

\section{Dear Editor,}

We read with great interest the recent article by $\mathrm{Yu}$ and Chae [1], titled "The mediating effect of resilience on the relationship between academic burnout and psychological well-being of medical students." This is an important topic and we commend the authors on conducting valuable research into this area. As medical students at King's College London in the United Kingdom, our anecdotal experience parallels the findings of this study. Our experience has been that academic burnout is inextricably linked with psychological well-being. Additionally, we have too found that burnout is greater during pre-clinical years.

In the Korean medical student cohort, the authors hypothesise the reason for the difference in academic burnout seen between preclinical and clinical medical students could be due to the frequency of examinations. However, in our experience we have had the same frequency of examinations throughout all years of medical school, yet still found higher levels of academic burnout during preclinical years. We therefore hypo- thesise other reasons for the higher academic burnout observed during preclinical years. These may include that the total amount of content to learn during preclinical years is greater than clinical years. Additionally, difference in content covered may be responsible, as medical students we find the clinical applications of the theory most fascinating and enjoyable, and learning all the preclinical sciences (biochemistry, physiology, anatomy) in isolation to the clinical theory is occasionally challenging and difficult to remain enthused by.

King's College London, is one of a growing number of medical schools employing "Progress Testing" as the choice of examinations for medical students since the introduction of a new medical curriculum in 2016. Progress tests were first introduced in the 1970s and are formative assessments of graduate learning outcomes conducted at frequent intervals throughout the medical curriculum. Progress tests have been associated with reduced stress in comparison to traditional high-stakes examinations [2]. Progress tests are associated with increased long-term retention of information in com-
Received: March 28, 2020 • Revised: April 26, 2020 • Accepted: May 13, 2020 Corresponding Author: Sanketh Rampes (https://orcid.org/0000-0002-6116-8531) Faculty of Life Sciences \& Medicine, King's College London, London, SE1 1UL, UK Tel: +44.20.7836.5454 Fax: +44.20.7836.5454 email: sanketh.rampes@kcl.ac.uk
Korean J Med Educ 2020 Sep; 32(3): 261-263.

https://doi.org/10.3946/kjme.2020.174

eISSN: 2005-7288

(C) The Korean Society of Medical Education. All rights reserved. This is an open-access article distributed under the terms of the Creative Commons Attribution Non-Commercial License (http:// creativecommons.org/licenses/by-nc/3.0/), which permits unrestricted non-commercial use, distribution, and reproduction in any medium, provided the original work is properly cited. 
parison with traditional examinations [3]. Some authors of this letter have completed prior degrees where traditional examinations were used, and their personal experience is that progress testing is associated with reduced stress and burnout when compared to traditional exams. Therefore, we suggest that progress tests may be a solution to reduce burnout amongst medical students.

When analysing the multiple regression analysis performed by the authors to determine whether resilience mediated the relationship between academic burnout and psychological well-being, we noticed that that the authors had not included an interaction term between the two predictor variables resilience and academic burnout. The authors had demonstrated that resilience predicted academic burnout, thus suggesting a relationship between the two variables. Therefore, we question why an interaction term was not included in the multiple regression analysis.

This research adds to the evidence suggesting an important role of resilience in medical training. The American Psychological Association (2014) defined resilience as "the process of adapting well in the face of adversity, trauma, tragedy, threats, or even significant sources of stress (paragraph 4)" [4]. A literature review found that the strongest evidence for increasing resilience is through the use of resilience workshops and cognitive behavioural interventions [5]. Another paper found that changing student perspectives, by normalising stress would be a helpful way to increase resilience [6]. This is something that we agree with; from our own experience of starting medical school we found that no one gave us realistic expectations of the workload, and what level of knowledge is required to make a good doctor. Although memorising every enzyme involved in the Krebs cycle, or the genetic mutations involved in rare genetic diseases may help students to excel in exams, does this translate to being an excellent doctor?
The answer is most probably not.

To conclude, we believe that resilience training should be built into the medical curriculum. Resilience should be tackled both at a university and individual level. At a university level resilience workshops as described in the literature should be employed [6]. Additionally, universities could facilitate mentorship programmes between medical students; an example could be pairing medical students with senior medical students several years ahead of themselves. This will enable students to benefit from the experience of their peers, through changing perspectives and receiving practical advice how to cope at medical school. Additionally, some research suggests mentorship may reduce academic burnout [7]. On an individual level, medical students should focus on strategies known to promote resilience such as developing trait mindfulness, engaging in physical exercise and developing a rich social support network [8]. We should also remember that although resilience training is important, it is only part of the solution; the other part of the solution is to correct organisational pathologies and engage doctors in the co-creation of work systems which allow for improved mental well-being [9].

\section{ORCID:}

Sanketh Rampes: https://orcid.org/0000-0002-6116-8531;

Anvarjon Mukhammadaminov: https://orcid.org/0000-0002-2394-1175;

Kitt Dokal: https://orcid.org/0000-0002-2516-0823;

Samineh Yousefi: https://orcid.org/0000-0002-9093-2703;

Yasmin Amy Divecha: https://orcid.org/0000-0002-3541-0339

Acknowledgements: None.

Funding: No funding provided for this research.

Conflicts of interest: No potential conflict of interest relevant to this article was reported.

Author contributions: All authors contributed equally in 
the conception and design of this work, and writing of the manuscript.

\section{References}

1. Yu J, Chae S. The mediating effect of resilience on the relationship between the academic burnout and psychological well-being of medical students. Korean J Med Educ. 2020;32(1):13-21.

2. Chen Y, Henning M, Yielder J, Jones R, Wearn A, Weller J. Progress testing in the medical curriculum: students' approaches to learning and perceived stress. BMC Med Educ. 2015;15:147.

3. Van der Vleuten CP, Verwijnen GM, Wijnen WH. Fifteen years of experience with progress testing in a problem-based learning curriculum. Med Teach. 1996; 18(2):103-109.
4. American Psychological Association. Building your resilience. https://www.apa.org/topics/resilience. Published February 2020. Accessed March 24, 2020.

5. Rogers D. Which educational interventions improve healthcare professionals' resilience? Med Teach. 2016; 38(12):1236-1241.

6. Farquhar J, Kamei R, Vidyarthi A. Strategies for enhancing medical student resilience: student and faculty member perspectives. Int J Med Educ. 2018;9:1-6.

7. Jordan J, Watcha D, Cassella C, Kaji AH, Trivedi S. Impact of a mentorship program on medical student burnout. AEM Educ Train. 2019;3(3):218-225.

8. Wu G, Feder A, Cohen $\mathrm{H}$, et al. Understanding resilience. Front Behav Neurosci. 2013;7:10.

9. Card AJ. Physician burnout: resilience training is only part of the solution. Ann Fam Med. 2018;16(3): 267-270. 